\title{
(2) OPEN ACCESS \\ Potential impact of eliminating illicit trade in cigarettes: a demand-side perspective
}

\author{
Mark Goodchild (1) , Jeremias Paul, Roberto Iglesias, Annerie Bouw, \\ Anne-Marie Perucic
}

- Additional material is published online only. To view please visit the journal online (http://dx.doi.org/10.1136/ tobaccocontrol-2020-055980)

Health Promotion Department World Health Organization, Geneva, Switzerland

\section{Correspondence to}

Mark Goodchild, World Health Organization, Geneva 1211,

Switzerland;

goodchildm@who.int

Received 3 June 2020

Revised 14 September 2020

Accepted 18 September 2020
A Check for updates

(c) Author(s) (or their employer(s)) 2020. Re-use permitted under CC BY-NC. No commercial re-use. See rights and permissions. Published by BMJ.

To cite: Goodchild M, Paul J, Iglesias R, et al. Tob Control Epub ahead of print: [please include Day Month Year]. doi:10.1136/

tobaccocontrol-2020-055980

\section{ABSTRACT \\ Background The Protocol to Eliminate Illicit Trade in Tobacco Products (the Protocol) entered into force in September 2018, and commits Parties to implement a package of measures to combat this global problem. The aim of this study is to assess the potential impact of eliminating illicit cigarettes on consumption, use and tax revenues.}

Methods We identified 36 countries where an independent (non-industry sponsored) study of the illicit cigarette market was available. We developed a conceptual framework for describing how the elimination of illicit cigarettes might impact on demand (consumption and use) and applied this framework to our sample of countries to assess the impact of eliminating illicit cigarettes across different settings. Findings Illicit cigarettes account on average for $11.2 \%$ of the market in these 36 countries. The elimination of illicit cigarettes would reduce total cigarette consumption by $1.9 \%$ across these countries. The decrease in 'group $A^{\prime}$ countries-where illicit cigarettes are $>15 \%$ of the market—would average $4.1 \%$. The smoking rate would decrease by $1.0 \%$ in relative terms including by $2.2 \%$ in group A countries. Tax revenues from the legal sale of cigarettes would increase by $11.2 \%$ including by $25.1 \%$ in group A countries.

Conclusions The illicit cigarette market reflects a complex interplay between supply and demand, with an array of different country conditions. Regardless of the situation, our study highlights the contribution that the elimination of illicit trade can make to tobacco control through demand reduction while at the same time generating significant tax revenues.

\section{INTRODUCTION}

It has been a decade since the influential study by Joossens $e t a l,{ }^{1}$ on the global illicit cigarette market was published. Based on a sample of 84 countries, the study found that $11.6 \%$ of the world's cigarette market was illicit. The study also found that eliminating illicit trade in cigarettes globally would reduce cigarette consumption by $2 \%$, generate at least US $\$ 31$ billion in tax revenues, and prevent millions of deaths.

There has since been a proliferation of studies on illicit cigarette markets including in low-income and middle-Income countries (LMICs). Many of these studies have focused on the elusive link between cigarette prices and the illicit market. One study found, for example, that the median price of illicit cigarettes was in fact higher than legal cigarettes in six LMICs (Bangladesh, India, Pakistan,
Philippines, Thailand and Vietnam), but lower in three (Turkey, Ukraine and China). ${ }^{2}$

The authors highlighted taste and brand preference by consumers as likely contributory factors in countries where the price of illicit cigarettes is higher, while also noting that the illicit market is not a homogeneous entity. ${ }^{2}$ The study by Joossens et $a l^{1}$ focused on smuggling of premium cigarettes thought to dominate the illicit market at the time. Other sources of illicit trade have since emerged including illegal or undeclared manufacturing. ${ }^{3}$

The past decade also saw the entry into force of the Protocol to Eliminate Illicit Trade in Tobacco Products (the Protocol). ${ }^{45}$ There are currently 61 Parties to the Protocol, which commits them to implement a package of counter measures including enhanced international cooperation. The Protocol undoubtedly creates further impetus for monitoring illicit tobacco markets.

The aim of this paper is to assess the potential impact of eliminating illicit cigarettes on health (via the rate of smoking) and tax revenues. While the complete elimination is unrealistic at least in the short-to-medium-term, we used this scenario because it is most consistent with the Protocol and any lesser number would be arbitrary in any case. We develop a conceptual framework for describing how these impacts may occur, and apply this framework to a sample of countries to assess the impact of eliminating illicit cigarettes in different settings. We focus on the rate of smoking in this framework as this is the key trace indicator for determining downstream health and economic impacts relating to the burden of disease. The elimination of illicit cigarettes is thus conceptually linked to improvements in such health and economic outcomes.

This is not a full cost-benefit analysis since the cost of Protocol measures are not included, but it is a step in this direction. Our study does highlight the importance of the Protocol to achieving tobacco control. This is relevant not just to Parties to the Protocol, but also to global health objectives such as targets 3a. and 3.4 of the Sustainable Development Goals (SDGs) and the WHO Global noncommunicable diseases (NCD) Action Plan, which sets a voluntary target for countries to reduce tobacco use by $30 \%$ by $2025 .^{67}$

\section{METHODS}

Our first step was to undertake a literature review to identify independent (non-industry sponsored) studies of illicit cigarette markets in different countries. We searched several bibliographic databases, including PubMed, and two thematic journals (BMJ 
Table 1 Independent studies of illicit cigarette markets over the past decade

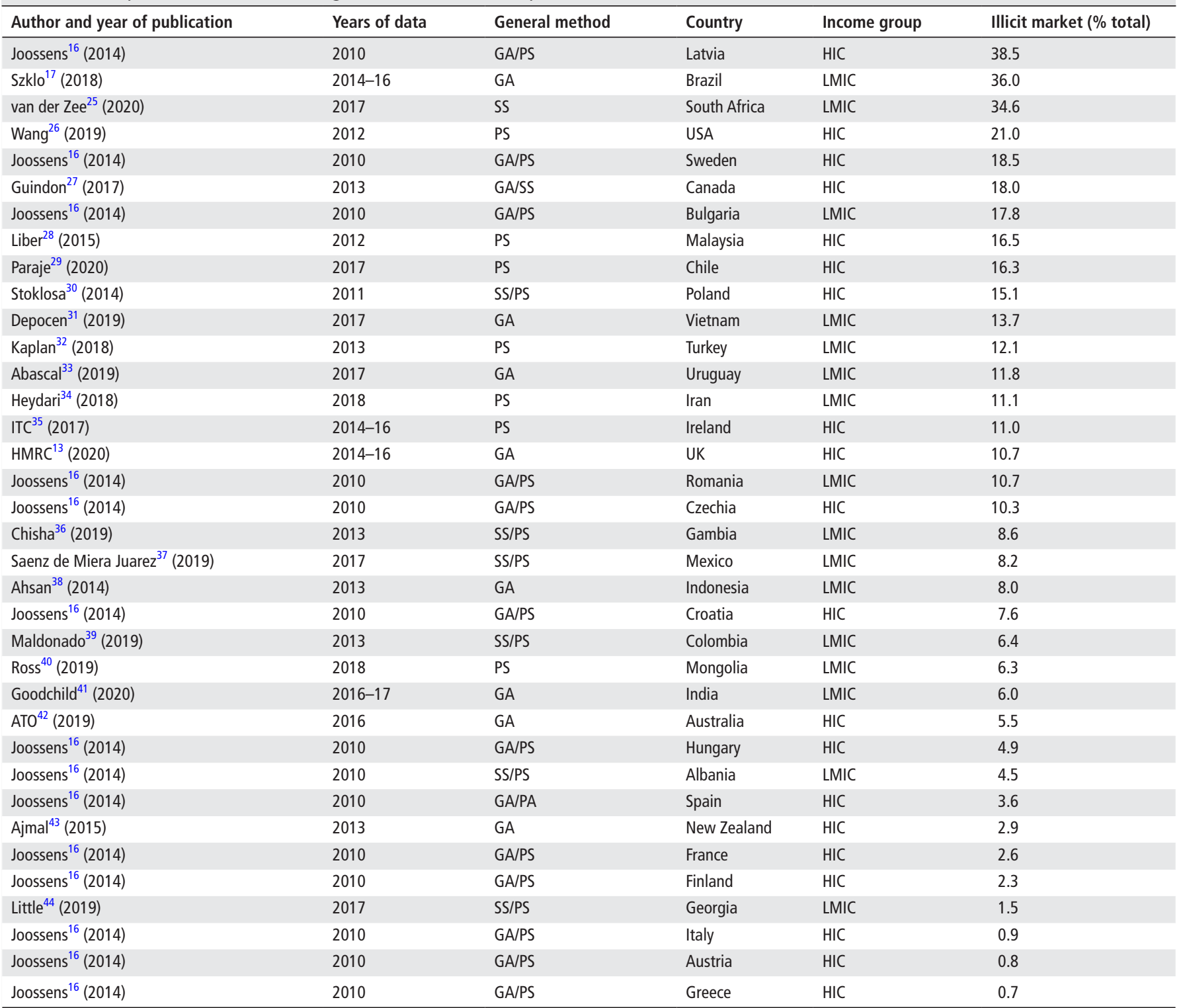

GA, gap analysis; HIC, high income country; LMIC, low and middle income country; PS, pack survey; SS, smokers survey.

Tobacco Control and the Journal of the Society for Research into Nicotine \& Tobacco) using search terms-illicit, smuggling, cigarette, tobacco. In addition, we searched Google for grey literature, particularly studies by government institutions.

We limited our sample to studies using data within the past 10 years taking data points as close as possible to 2015. Table 1 presents the studies that were identified together with key descriptive information. Note some studies, such as those for Chile and South Africa, focus on certain locations or population groups, and thus are not necessarily nationally representative.

Next, we established a baseline of each country (i) by estimating the absolute number of illicit cigarettes $\left(\mathrm{IC}_{\mathrm{i}}\right)$ :

$$
\mathrm{IC}_{\mathrm{i}}=\left(\mathrm{MS}_{\mathrm{i}} \times \mathrm{LC}_{\mathrm{i}}\right) \div\left(1-\mathrm{MS}_{\mathrm{i}}\right)
$$

where $\left(\mathrm{MS}_{\mathrm{i}}\right)$ is the market share of illicit cigarettes in table 1 and $\left(\mathrm{LC}_{\mathrm{i}}\right)$ is the number of legal cigarettes sold in 2018 sourced from GlobalData Public Limited Company (PLC). ${ }^{8}$ The equivalent number of illicit smokers was estimated in 2018 assuming they initially have the same intensity of smoking as the whole smoking population. There are some limitations to this assumption including that it does not allow for possible dual use of illicit and legal products by smokers. There is also some evidence to suggest that heavier, more addicted smokers are likelier to engage in tax avoidance. ${ }^{9}$ Nonetheless, our initial assumption is a reasonable starting point across all countries and illicit situations, and we subsequently allow the smoking intensity of illicit smokers to decrease in response to price changes.

Figure 1 presents our conceptual framework of the different path's smokers might take in response to the elimination of illicit cigarettes. The established pathway highlighted in Joossens et $a l^{1}$ is for illicit smokers to switch to a higher-priced brand in the legal market, with the resulting price increase leading to reduced participation (use) and conditional demand (intensity). We have included two other potential pathways in our framework, including the possibility that some illicit smokers may quit outright in response to illicit counter measures much like they can do in response to traditional demand reduction measures included in the WHO Frame Work Convention on Tobacco Control (WHO FCTC) and MPOWER. ${ }^{10}$ This could include, 


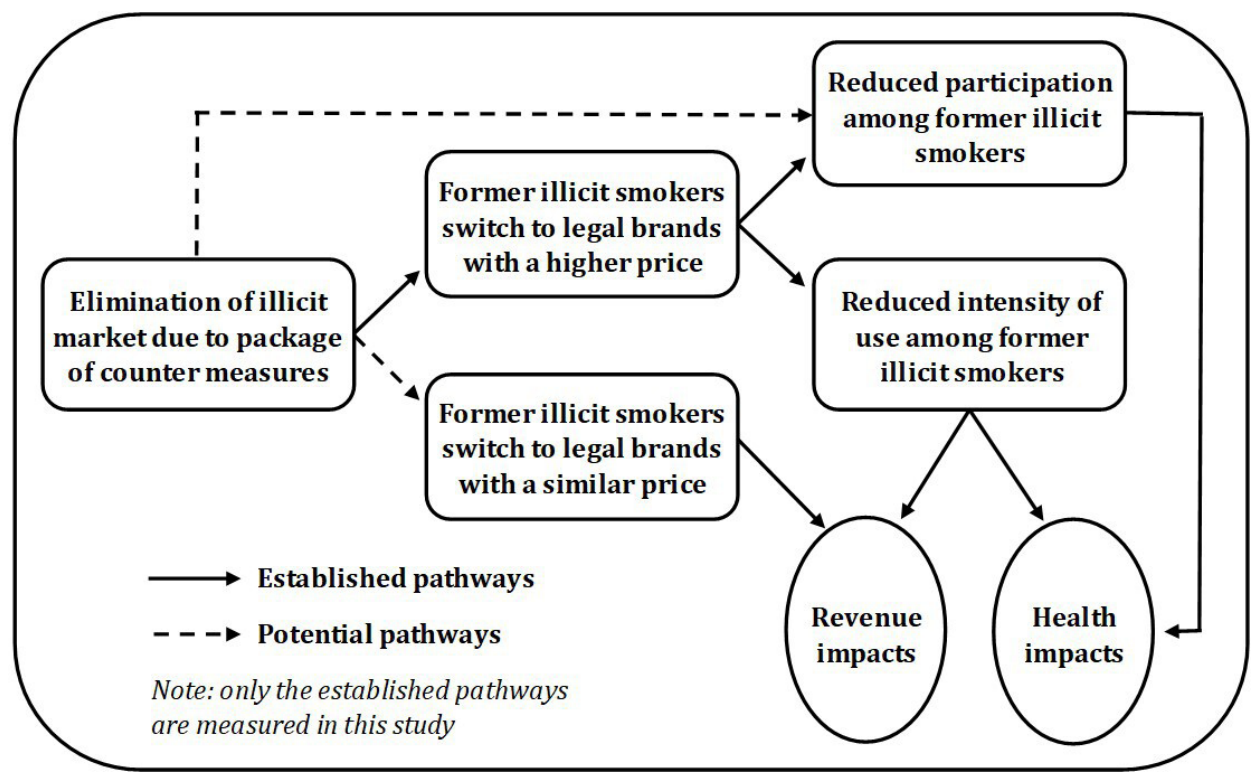

Figure 1 Framework for impact of eliminating illicit trade in cigarettes.

for example, such counter measures raising consumer awareness or search costs.

The second potential pathway highlights that some smokers of illicit cigarettes may switch to a legal pack with similar prices, leading to little change in price or consumption levels. This acknowledges that the choices smokers make also depend on non-price factors such as perceived quality (taste, preference, etc). Hence, some illicit smokers may compromise on perceived quality, for example, by switching from an illicit foreign pack to a similarly priced legal domestic brand. This incorporates evidence from some countries that illicit packs can be higher priced than legal ones, while recognising that we do not really know the 'second-best' choice of illicit smokers.

There is relatively little knowledge about the relative strength or importance of these different pathway's at present, and such evidence will need to come either from country-level experience or perhaps discrete experiments to test consumer choices and preferences. Consequently, we still focus on the established pathway (the impact of higher prices as smokers switch to the legal market) in terms of our quantitative analysis and return to other pathways in the discussion.

However, we do segment the illicit market according to broad price levels. That is, between consumers of low-price illicit packs and consumers of other (mid-price and high-price) illicit packs. We do this to make our estimation of the revenue gains more accurate by incorporating different tax yields for low versus midprice/high-price packs. It also enables us to incorporate different price responses as smokers of low-price packs tend to be from lower income populations and thus more price sensitive. ${ }^{11}$

It is also interesting to segment the illicit market this way because smokers of the lowest price illicit packs have fewer options other than to experience a strong price increase when they switch to the legal market. On the other hand, smokers of mid-price/high-price illicit packs likely have more latitude as discussed.

Our low-price illicit pack categorisation includes, but is not limited to, 'cheap white' cigarettes. Cheap whites are legally manufactured but sold without all applicable duties, usually outside of the jurisdiction where they were produced. ${ }^{12}$ Cheap whites have been highlighted as a growing problem in the European Union. Ireland, for example, reports that cheap whites accounted for $22 \%$ of the illicit market in 2017, up from $12 \%$ in 2012. ${ }^{13}$ Similarly, World Customs Organization data suggested that cheap whites accounted for about $25 \%$ of global seizures in 2012. ${ }^{14}$ However, other studies have found mixed trends for cheap whites for various countries in the European Union. ${ }^{15}$

The proportion of low-price illicit packs relative to the entire illicit market can be found in several studies from our sample. For example, studies for Brazil, Gambia, Malaysia and Mexico include minimum legal prices as an indicator of illicit packs. Similarly, another study by Joossens et $a l^{16}$ reported the proportion of cheap illicit cigarettes based on whether respondents reported purchasing prices that were less than $70 \%$ of the cheapest legal brand in each country.

Table 2 shows the estimated proportion of lowest price illicit cigarettes in the total illicit market for each country, within a range of $5 \%-95 \%$ of the illicit market. Based on a comparison of two studies of the Brazilian market for 2013, Brazil is estimated to have the highest proportion of low-price cigarettes in its illicit market. ${ }^{17} 18$ On the other hand, 8 countries reported proportions of less than $10 \%$ for low price cigarettes. Countries without such information were generally assigned a value of $33 \%$ (the median across all countries with available data). Table 2 also shows the average tax per pack (US\$/20 sticks) applicable on the cheapest and most sold brands in each country from the 2019 WHO Report Global Tobacco Epidemic (GTCR). ${ }^{10}$

Returning to figure 1 , the critical juncture in terms of health impact relates to those smokers who respond to a higher price by quitting altogether-cessation-versus those who respond by reducing their intensity of use. This juncture depends on several factors, including the price change itself and the smokers price elasticity of demand for cigarettes.

Joossens et al ${ }^{1}$ assessed the price of illicit packs from a number of studies available at the time, and developed a benchmark that the price of illicit packs was equivalent to the price of legal packs minus two-thirds of the tax. We applied this benchmark to tax and price data on the most sold brand in 178 countries from the GTCR and found that it implies illicit cigarettes are 65\% (95\% CI $63 \%$ to $67 \%$ ) of the price of legal cigarettes. ${ }^{10}$ Expressed another way, illicit smokers would experience a 53\% $95 \% \mathrm{CI}$ $48 \%$ to $58 \%$ ) price increase when switching to the legal market. 


\begin{tabular}{|c|c|c|c|c|c|}
\hline $\begin{array}{l}\text { Source of lowest price as a share of } \\
\text { illicit market }\end{array}$ & Country & Income group & $\begin{array}{l}\text { Lowest price } \\
\text { (\% illicit market) }\end{array}$ & $\begin{array}{l}\text { Tax/pack } \\
\text { (cheapest) }\end{array}$ & Tax/pack (MSB) $\ddagger$ \\
\hline Joossens et al ${ }^{16}$ (2014) & Latvia & HIC & 53 & 3.1 & 3.3 \\
\hline Iglesias et al ${ }^{18}(2017)$ & Brazil & LMIC & 95 & 1.1 & 1.3 \\
\hline van der Zee et a $l^{25}(2020)$ & South Africa & LMIC & 22 & 1.4 & 1.6 \\
\hline Median (all countries) $\dagger$ & USA & $\mathrm{HIC}$ & 33 & 2.8 & 2.9 \\
\hline Joossens et al ${ }^{16}$ (2014) & Sweden & HIC & 5 & 4.8 & 5.1 \\
\hline Median (all countries) & Canada & HIC & 33 & 5.5 & 5.8 \\
\hline Joossens et al ${ }^{16}$ (2014) & Bulgaria & LMIC & 13 & 2.4 & 2.6 \\
\hline Liber et al ${ }^{28}$ (2015) & Malaysia & HIC & 92 & 2.1 & 2.5 \\
\hline Median (all countries) & Chile & HIC & 33 & 3.1 & 3.5 \\
\hline Joossens et al ${ }^{16}$ (2014) & Poland & HIC & 35 & 2.9 & 3.3 \\
\hline Depocen $^{31}$ (2019) & Vietnam & LMIC & 5 & 0.1 & 0.3 \\
\hline Kaplan et $a^{32}$ (2018) & Turkey & LMIC & 84 & 1.3 & 2.2 \\
\hline Iglesias et al ${ }^{18}(2017)^{*}$ & Uruguay & LMIC & 95 & 3.0 & 3.0 \\
\hline Heydari" ${ }^{34}$ (2018) & Iran & LMIC & 5 & 0.1 & 0.2 \\
\hline Joossens et al ${ }^{16}$ (2014) & Ireland & HIC & 35 & 10.5 & 11.2 \\
\hline Joossens et al ${ }^{16}$ (2014) & UK & HIC & 12 & 9.0 & 9.8 \\
\hline Joossens et a $\left.\right|^{16}(2014)$ & Romania & LMIC & 22 & 2.9 & 3.0 \\
\hline Joossens et al ${ }^{16}$ (2014) & Czechia & HIC & 5 & 3.0 & 3.3 \\
\hline Chisha et $a^{36}$ (2019) & Gambia & LMIC & 7 & 0.5 & 0.6 \\
\hline Median (all countries) & Mexico & LMIC & 33 & 1.0 & 1.8 \\
\hline Median (all countries) & Indonesia & LMIC & 33 & 0.3 & 1.1 \\
\hline Joossens et al/ ${ }^{16}(2014)$ & Croatia & HIC & 5 & 2.3 & 3.1 \\
\hline Median (all countries) & Colombia & LMIC & 33 & 1.0 & 1.1 \\
\hline Median (all countries) & Mongolia & LMIC & 33 & 0.4 & 0.5 \\
\hline Median (all countries) & India & LMIC & 33 & 1.1 & 1.5 \\
\hline Median (all countries) & Australia & HIC & 33 & 12.0 & 12.0 \\
\hline Joossens et al ${ }^{16}$ (2014) & Hungary & HIC & 5 & 2.9 & 3.3 \\
\hline Joossens et $\mathrm{al}^{16}$ (2014) & Albania & LMIC & 16 & 1.4 & 1.5 \\
\hline Joossens et al ${ }^{16}$ (2014) & Spain & HIC & 12 & 3.8 & 4.6 \\
\hline Median (all countries) & New Zealand & HIC & 33 & 13.2 & 13.4 \\
\hline Joossens et al ${ }^{16}$ (2014) & France & HIC & 86 & 7.5 & 7.7 \\
\hline Joossens et al ${ }^{16}$ (2014) & Finland & HIC & 68 & 6.8 & 7.4 \\
\hline Median (all countries) & Georgia & LMIC & 33 & 0.4 & 1.1 \\
\hline Joossens et al ${ }^{16}$ (2014) & Italy & HIC & 27 & 3.7 & 4.9 \\
\hline Joossens et al ${ }^{16}$ (2014) & Austria & HIC & 5 & 4.2 & 4.9 \\
\hline Joossens et al ${ }^{16}$ (2014) & Greece & HIC & 80 & 4.0 & 4.4 \\
\hline
\end{tabular}

${ }^{*}$ Brazil used as a reference country for Uruguay rather than the median across all countries.

†Median: Authors estimates from countries with available data.

¥Tax/pack in US\$ from GTCR 2018.

GTCR, Report Global Tobacco Epidemic; HIC, high income country; LMIC, low and middle income country.

We also explored the evidence from our sample, with table 3 showing the price difference in 10 countries from studies which reported the necessary data. Note we used several different comparators because we were curious to see if there was any difference depending on study methodology. The price of illicit packs among these countries ranged from $48 \%$ to $71 \%$ of the price of legal packs in Turkey and Brazil, respectively. On average-across the 10 countries-illicit packs accounted for $63 \%$ of the price of legal packs, implying a $59 \%$ increase in price due to switching to legal packs.

The results are remarkably consistent with Joossens benchmark, including when different comparators were used in the studies. Taking all of this into consideration, we assume that smokers of low-price illicit packs will face a 55\% price increase when shifting to the legal market. To be consistent with our framework, we also assume that smokers of mid-price/highprice illicit packs will face a smaller $27.5 \%$ price increase when shifting to the legal market. In addition, we report upper and lower range estimates on the assumption that these smokers face a price increase of between $0 \%$ and $55 \%$. We also address the likelihood that smokers of cheapest illicit packs will curtail their smoking the most in the following discussion of price elasticities.

The impact of price increases on consumption is ultimately determined by the price elasticity of demand, with empirical studies indicating that such elasticities cluster around -0.4 in HICs and -0.5 in LMICs. ${ }^{10} 11$ This means that a $10 \%$ increase in cigarette prices, for example, will reduce consumption by 4\%-5\%. The finding that smokers in LMICs are more 'price sensitive' is also consistent with cross-sectional studies where lower income smokers have higher price elasticities than medium-and-high-income smokers. ${ }^{11} 19$ We adapt these findings to the illicit market by applying the following price elasticities: -0.8 for smokers of lowest price illicit packs in LMICs; -0.5 
Table 3 Comparison illicit and legal prices in countries with available data

\begin{tabular}{|c|c|c|c|c|c|}
\hline Source of primary data on prices & Country & Illicit price (PPP/pack) & Legal price (PPP/pack) & Difference (\% of legal) & Implied increase (\%) \\
\hline Iglesias et al ${ }^{18}(2017)$ & Brazil $^{*}$ & 1.2 & 1.7 & 71 & 40 \\
\hline Joossens et al ${ }^{16}$ (2014) & Francet & 4.2 & 6.0 & 70 & 43 \\
\hline Chisha et $a l^{36}$ (2019) & Gambia* & 3.7 & 5.5 & 68 & 48 \\
\hline Brown et al $l^{2}(2017)$ & Russiał & 2.7 & 4.0 & 67 & 49 \\
\hline Brown et al ${ }^{2}(2017)$ & China & 3.1 & 4.7 & 66 & 52 \\
\hline Saenz de Miera Juarez et $\left.a\right|^{37}$ (2019) & Mexicot & 3.4 & 5.2 & 65 & 53 \\
\hline Brown et al ${ }^{2}(2017)$ & Ukraineł & 3.0 & 4.8 & 62 & 61 \\
\hline Liber et $a l^{28}(2015)$ & Malaysia* & 3.0 & 4.9 & 69 & 65 \\
\hline van der Zee et al $\left.\right|^{25}(2020)$ & South Africa* & 1.6 & 3.2 & 50 & 100 \\
\hline Kaplan et a/32 (2018) & Turkey§ & 2.0 & 4.1 & 48 & 109 \\
\hline Authors estimate & Average & 2.8 & 4.4 & 63 & 59 \\
\hline
\end{tabular}

*Illicit prices versus minimum legal price.

†lllicit prices versus cheapest legal brand.

¥Median illicit price versus median legal price.

$\S$ Packs with versus without stamps.

PPP, purchasing power parity or international dollars.

for other illicit packs in LMICs; -0.7 for lowest price illicit packs in HICs and -0.4 for other illicit packs in HICs.

The price elasticity of demand reflects a mix of conditional demand (the intensity of smoking) and the number of smokers (participation). The available empirical evidence shows that about half of the reduction in cigarette consumption from a given price increase is due to a decrease in conditional demand, while the other half is due to a reduction in prevalence (ie, cessation). ${ }^{11}$ Consequently, the price prevalence elasticity of demand is about half of the given price elasticity. ${ }^{20-22}$ We apply this rule to the price elasticities above, giving price prevalence elasticities ranging from -0.2 for other illicit packs in HICs to -0.4 for lowest price illicit packs in LMICs. Note a detailed country example is provided in the online supplemental file.

Finally, the impact on tax revenues is calculated by multiplying the increase in legal cigarette consumption at the cheap and mid/ high end of the market by the applicable tax per pack in US\$ (table 2). Consequently, we calculate the gain in tax revenue after accounting for changes in consumption as illicit smokers switch to higher priced legal packs, while also recognising that some smokers will enter the legal market at different price points thus impacting tax yields.

\section{FINDINGS}

Figure 2 presents the market share of illicit cigarettes in the countries from our sample, together with the simple average of $11.2 \%$ across all of these countries. This is consistent with Joossens et $\mathrm{al}^{1}$ where illicit cigarettes were calculated to be $11.6 \%$ of the global market. We also find some differences by income level in our sample of countries, with illicit cigarettes averaging $10.4 \%$ and $12.3 \%$ in HICs and LMICs, respectively.

Table 4 shows the modelled impact of eliminating the illicit cigarette market on these countries and groups. On average, the increase in prices faced by illicit smokers due to the elimination of the illicit market would decrease total cigarette consumption by $1.9 \%$, within a range of between $1.2 \%$ and $2.4 \%$. The decrease would be much greater in group A countries at $4.1 \%$

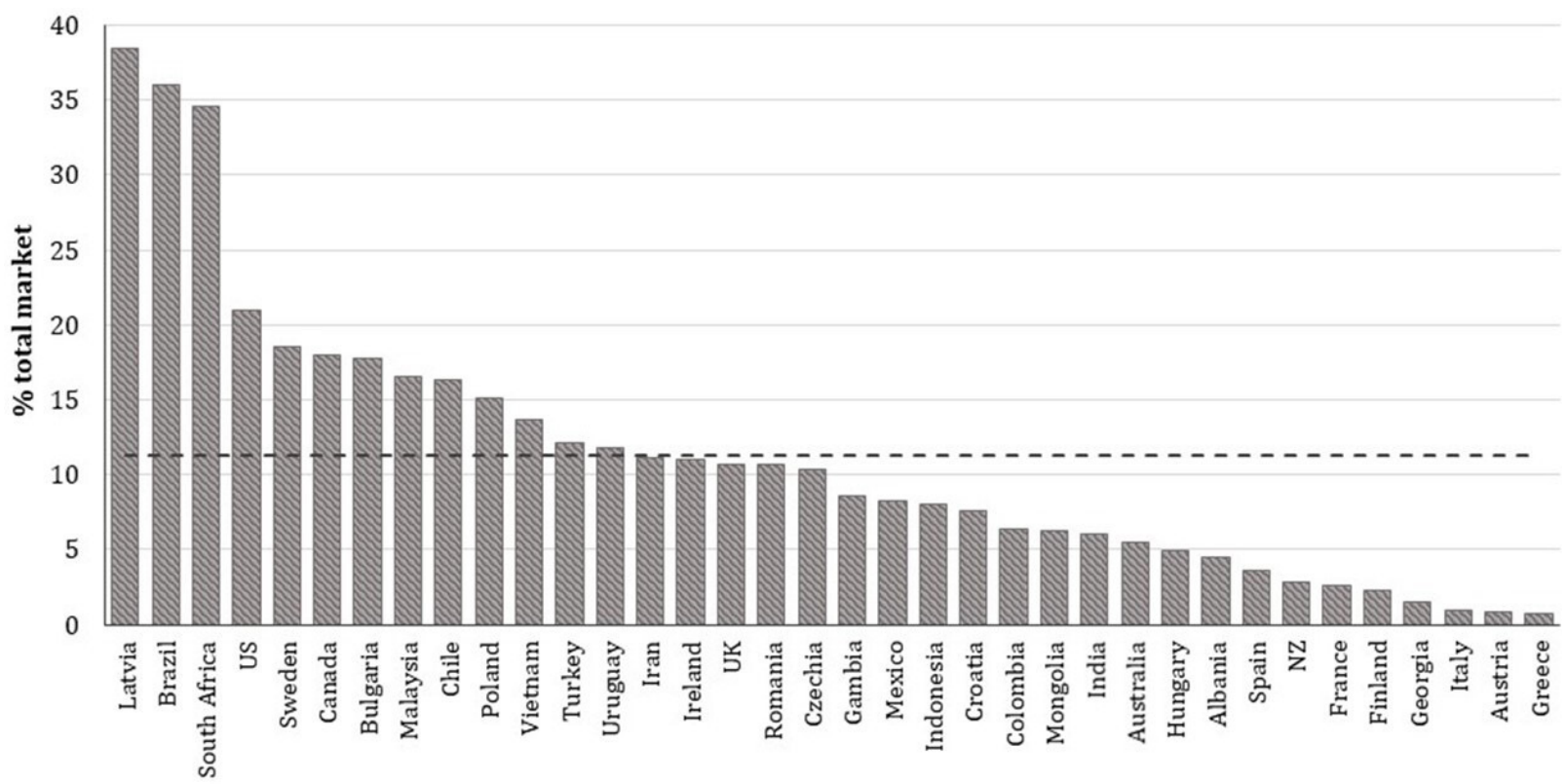

Figure 2 Studies of illicit cigarette markets with simple average. 


\begin{tabular}{|c|c|c|c|c|}
\hline Country & $\begin{array}{l}\text { All cigarettes } \\
\text { ( } \% \text { change) }\end{array}$ & $\begin{array}{l}\text { Total smokers } \\
\text { (\% change) }\end{array}$ & $\begin{array}{l}\text { Tax revenue } \\
\text { (\% change) }\end{array}$ & $\begin{array}{l}\text { Tax revenue } \\
\text { (US\$ Mn)* }\end{array}$ \\
\hline Latvia & -7.0 & -3.7 & 50.0 & 135 \\
\hline Brazil & -10.3 & -5.5 & 34.1 & 1326 \\
\hline South Africa & -5.3 & -2.8 & 43.7 & 668 \\
\hline USA & -3.1 & -1.6 & 22.3 & 8084 \\
\hline Sweden & -1.9 & -1.0 & 20.4 & 246 \\
\hline Canada & -2.7 & -1.4 & 18.4 & 1337 \\
\hline Bulgaria & -2.4 & -1.3 & 18.6 & 324 \\
\hline Malaysia & -4.1 & -2.2 & 13.0 & 116 \\
\hline Chile & -2.4 & -1.3 & 16.0 & 334 \\
\hline Poland & -2.3 & -1.2 & 14.6 & 992 \\
\hline Vietnam & -1.7 & -0.9 & 13.5 & 195 \\
\hline Turkey & -3.2 & -1.7 & 6.6 & 697 \\
\hline Uruguay & -3.4 & -1.8 & 9.4 & 29 \\
\hline Iran & -1.4 & -0.7 & 10.8 & 57 \\
\hline Ireland & -1.7 & -0.9 & 10.3 & 165 \\
\hline UK & -1.2 & -0.6 & 10.6 & 1412 \\
\hline Romania & -1.6 & -0.9 & 10.0 & 362 \\
\hline Czechia & -1.0 & -0.5 & 10.3 & 335 \\
\hline Gambia & -1.1 & -0.6 & 8.1 & 1 \\
\hline Mexico & -1.4 & -0.8 & 6.5 & 327 \\
\hline Indonesia & -1.4 & -0.7 & 5.6 & 908 \\
\hline Croatia & -0.8 & -0.4 & 7.3 & 77 \\
\hline Colombia & -1.1 & -0.6 & 5.5 & 35 \\
\hline Mongolia & -1.1 & -0.6 & 5.3 & 2 \\
\hline India & -1.0 & -0.6 & 4.8 & 320 \\
\hline Australia & -0.8 & -0.4 & 5.0 & 432 \\
\hline Hungary & -0.5 & -0.3 & 4.6 & 44 \\
\hline Albania & -0.6 & -0.3 & 4.0 & 9 \\
\hline Spain & -0.4 & -0.2 & 3.3 & 353 \\
\hline New Zealand & -0.4 & -0.2 & 2.5 & 26 \\
\hline France & -0.6 & -0.3 & 2.0 & 341 \\
\hline Finland & -0.5 & -0.3 & 1.8 & 29 \\
\hline Georgia & -0.3 & -0.1 & 1.0 & 4 \\
\hline Italy & -0.1 & -0.1 & 0.7 & 123 \\
\hline Austria & -0.1 & -0.0 & 0.7 & 21 \\
\hline Greece & -0.2 & -0.1 & 0.5 & 16 \\
\hline \multirow[t]{2}{*}{ Group A } & -4.1 & -2.2 & 25.1 & 13563 \\
\hline & -2.9 to -5.1 & -1.5 to -2.7 & 23.9 to 26.8 & 12882 to 14509 \\
\hline \multirow[t]{2}{*}{ Group B } & -1.7 & -0.9 & 9.1 & 4564 \\
\hline & -0.9 to -2.2 & -0.5 to -1.2 & 8.5 to 9.9 & 4263 to 4986 \\
\hline \multirow[t]{2}{*}{ Group C } & -0.6 & -0.3 & 3.0 & 1757 \\
\hline & -0.3 to -0.7 & -0.2 to -0.4 & 2.8 to 3.2 & 1666 to 1885 \\
\hline \multirow[t]{2}{*}{ Average } & -1.9 & -1.0 & 11.2 & 19884 \\
\hline & -1.2 to -2.4 & -0.7 to -1.3 & 10.5 to 12.0 & 18810 to 21380 \\
\hline
\end{tabular}

*Totals with respect to tax revenues in final column.

(range 2.9\%-5.1\%), while the impact is less discernible in group C countries.

Table 4 shows the projected change in the number of cigarette smokers which can also be interpreted as the relative reduction in the smoking rate. On average, the number of smokers (rate of smoking) would decrease by $1.0 \%(0.7 \%$ to $1.3 \%)$, representing 3.9 million fewer smokers in this sample of countries. From a narrower perspective, our assessment also suggests that $10 \%$ of illicit smokers would quit altogether in response to these higher prices. Group A countries experience the greatest health gain, with the smoking rate decreasing in relative terms by $2.2 \%$
$(1.5 \%$ to $2.7 \%)$ in these countries. In terms of country income levels, the impact on the number of smokers is relatively greater in LMICs with an average decrease of $1.2 \%(0.8 \%$ to $1.6 \%)$ compared with HICs with an average decrease of $0.8 \%(0.5 \%$ to $1.1 \%)$.

Table 4 also shows the projected increase in tax revenues from legal cigarettes in these countries. On average, eliminating illicit cigarettes would increase tax revenues by $11.2 \%(10.5 \%$ to $12.0 \%)$, representing an extra US $\$ 19.9$ billion across these countries. Tax revenues in group A countries can increase quite substantially (by 25.1\%), with this group of countries accounting for two-thirds of the total US $\$ 19.9$ billion estimated gain. Many group B countries also experience a strong increase, with the average for this group being $9.1 \%$.

It is difficult to fully reconcile the revenue estimates with Joossens $e t a l^{1}$ due to differences in the number of countries sampled and the time interval between studies. Nonetheless, we broadly estimate that the global revenue potential from eliminating illicit cigarettes is about US $\$ 47.4$ billion today, compared with US $\$ 31$ billion in Joossens study. Our indicative figure was calculated by multiplying an earlier estimate from Goodchild et $a l^{20}$ that global cigarette tax revenues amounted to US $\$ 425$ billion in 2014 by the average increase of $11.2 \%$ as calculated above.

\section{DISCUSSION}

Eliminating the illicit cigarette market is an important goal for public health, including global strategies such as the WHO Global NCD Action Plan and targets 3.a and 3.4 of the SDGs. The positive impact of controlling illicit trade extends beyond health into other development areas such as good governance, justice and so forth. This study highlights the positive contribution that illicit counter measures can make to demand reduction, while at the same time generating significant tax revenues especially in high illicit countries.

This study also advances the literature in several ways including by highlighting different paths from a demand perspective. While there are many examples around the world of measures to combat illicit tobacco being highly successful especially in terms of tax revenues, more evidence is needed still in terms of demand reduction. ${ }^{23}{ }^{24}$ The conceptual framework recognises that such measures may have a direct effect on cessation like traditional demand reduction measures in the WHO FCTC and MPOWER, which in turn would mean the level of demand reduction could be greater than observed. Such evidence will likely emerge as countries scale-up their control efforts under the Protocol.

On the other hand, the framework also acknowledges that some illicit smokers may not necessarily experience a large price increase from the elimination of illicit cigarettes. This reflects the fact that the illicit market is quite heterogeneous in terms of price and perceived quality. Similarly, little is known about the choice's smokers will make in the absence of illicit cigarettes. We have addressed this partly by segmenting the market into low and mid-price/high-price packs, with the expectation that smokers of cheapest illicit packs are more likely to face a strong price increase.

However, in some countries, smokers of low-price illicit cigarettes may have substitute tobacco products that are lower in price than legal cigarettes available to them, for example, loose or roll-your-own tobacco across Europe. A reduction in the illicit market may also be associated with marketing strategies by the legal tobacco industry, for example, the offering of price discounts to attract consumption by weakening price increases faced by smokers. These examples highlight the need for more 
consistent tax and price policies on all tobacco products. A comprehensive strategy of tax increases in combination with strengthened illicit trade counter measures would also appear to be a highly effective way to promote demand reduction and to generate revenue.

\section{CONCLUSION}

The illicit cigarette market reflects a complex interplay between supply and demand, with an array of different country conditions. Regardless of the situation, scaling-up measures to counter illicit trade can make a significant contribution to tobacco control through demand reduction while at the same time generating significant tax revenues.

\section{What this paper adds}

What is already known on this subject

- There has been a proliferation of illicit trade studies over the past decade since Joossens et al (2009) found that illicit cigarettes accounted for $11.6 \%$ of the global cigarette market. The past decade also saw the entry into force of the Protocol to Eliminate Illicit Trade in Tobacco Products (the Protocol). The Protocol creates further impetus for measuring illicit tobacco markets, including the impact of illicit trade countermeasures.

What important gaps in knowledge exist on this topic

- The relationship between the illicit cigarette market and tobacco control policies, including measures to counter illicit trade, are still relatively elusive. This is partly because the illicit market can be quite heterogeneous, including country examples where the price of illicit cigarettes is higher than legal cigarettes. Such examples reflect demand-side considerations such as perceived quality (taste, status, etc) and the brand preference of smokers.

\section{What this paper adds}

- The aim of this paper is to assess the potential impact of eliminating illicit cigarettes on health (via the smoking rate) and tax revenues. We develop a conceptual framework for describing how these impacts may occur, and apply it to a sample of countries to assess the impact of eliminating illicit cigarettes across different settings. We find the elimination of illicit cigarettes would cause the smoking rate to decrease by $1.0 \%$ in relative terms, including by $2.2 \%$ in group $A$ countries (where illicit cigarettes account for $>15 \%$ of the market). Tax revenues from the sale of cigarettes would also increase by $11.2 \%$ including by $25.1 \%$ in group A countries.

Contributors MG led the design, data collection, analysis and write-up of the paper. JP, RI, AB and A-MP each contributed to the design, data collection and write up of the paper.

Funding The authors have not declared a specific grant for this research from any funding agency in the public, commercial or not-for-profit sectors.

Disclaimer The authors alone are responsible for the views expressed in this article and they do not necessarily represent the views, decisions or policies of the institutions with which they are affiliated.

Competing interests None declared.

Patient consent for publication Not required.

Provenance and peer review Not commissioned; externally peer reviewed.

Data availability statement All data relevant to the study are included in the article or uploaded as online supplemental information.

Open access This is an open access article distributed in accordance with the Creative Commons Attribution Non Commercial (CC BY-NC 4.0) license, which permits others to distribute, remix, adapt, build upon this work non-commercially, and license their derivative works on different terms, provided the original work is properly cited, appropriate credit is given, any changes made indicated, and the use is non-commercial. See: http://creativecommons.org/licenses/by-nc/4.0/.

\section{ORCID ID}

Mark Goodchild http://orcid.org/0000-0002-1826-1343

\section{REFERENCES}

1 Joossens L, Merriman D, Ross H, et al. How eliminating the global illicit cigarette trade would increase tax revenue and save lives. Paris: International Union Against Tuberculosis and Lung Disease, 2009. Available: https://untobaccocontrol.org/kh/ taxation/directory-e_library/listing/eliminating-global-illicit-cigarette-trade-increasetax-revenue-save-lives-4/ [Accessed 9 Feb 2020].

2 Brown J, Welding K, Cohen JE, et al. An analysis of purchase price of legal and illicit cigarettes in urban retail environments in 14 low- and middle-income countries. Addiction 2017;112:1854-60.

3 Joossens L, Raw M. From cigarette smuggling to illicit tobacco trade. Tob Control 2012;21:230-4.

4 WHO framework convention on tobacco control. Geneva: World Health Organization, 2003. Available: https://apps.who.int/iris/bitstream/handle/10665/42811/ 9241591013.pdf? sequence $=1$ [Accessed 30 May 2020].

5 Protocol to eliminate illicit trade in tobacco products. Geneva: World Health organization, 2013. Available: https://www.who.int/fctc/protocol/illicit_trade/protocolpublication/en/ [Accessed 30 May 2020].

6 Transforming our world: the 2030 agenda for sustainable development. New York: United Nations, 2015. Available: https://sustainabledevelopment.un.org/post2015/ transformingourworld/ [Accessed 30 May 2020].

7 Global action plan for the prevention and control of noncommunicable diseases 2013-2020. Available: https://www.who.int/nmh/events/ncd_action_plan/en/ [Accessed 30 May 2020].

8 Globaldata PLC. London. Available: http://.GlobalData.com [Accessed 20 Feb 2020].

9 Guindon GE, Driezen P, Chaloupka FJ, et al. Cigarette tax avoidance and evasion: findings from the International tobacco control policy evaluation (ITC) project. Tob Control 2014;23 Suppl 1:113-22.

10 WHO report on the global tobacco epidemic (GTCR). Geneva, World Health Organization, 2019. Available: https://www.who.int/tobacco/global_report/en// [Accessed 20 Feb 2020].

11 National Cancer Institute. The economics of tobacco and tobacco control. National cancer Institute tobacco control monograph 21. NIH publication No. 16-CA-8029A. Bethesda, MD: U.S. Department of Health and Human Services, National Institutes of Health, National Cancer Institute, 2016. Available: https://cancercontrol.cancer.gov/ brp/tcrb/monographs/21/index.html [Accessed 30 May 2020].

12 Ross H, Vellios N, Clegg Smith K, et al. A closer look at 'Cheap White' cigarettes. Tob Control 2016;25:527-31.

13 HMRC. Measuring tax gaps: tax gaps 2020 edition. London, HM Revenue and Customs Service, 2020. Available: https://assets.publishing.service.gov.uk/ government/uploads/system/uploads/attachment_data/file/907122/Measuring_tax_ gaps_2020_edition.pdf [Accessed 10 Aug 2020].

14 Gilmore AB, Gallagher AWA, Rowell A. Tobacco industry's elaborate attempts to control a global track and trace system and fundamentally undermine the illicit trade protocol. Tob Control 2019;28:127-40.

15 EC. Study on Council Directive 2011/64/EU on the structure and rates of excise duty applied to manufactured tobacco, final report, Vol 1. Brussels, European Commission, 2019. Available: https://ec.europa.eu/taxation_customs/sites/taxation/files/study_on_ directive-2011_64_main_text_en.pdf [Accessed 8 Apr 2020].

16 Joossens L, Lugo A, La Vecchia C, et al. Illicit cigarettes and hand-rolled tobacco in 18 European countries: a cross-sectional survey. Tob Control 2014;23:e17-23.

17 Szklo A, Iglesias RM, Carvalho de Souza M, et al. Trends in illicit cigarette use in Brazil estimated from legal sales, 2012-2016. Am J Public Health 2018;108:265-9.

18 Iglesias RM, Szklo AS, Souza MCde, et al. Estimating the size of illicit tobacco consumption in Brazil: findings from the global adult tobacco survey. Tob Control 2017:26:53-9

19 Fuchs A, Gonzalez Icaza FM, Paz DP. Distributional effects of tobacco taxation - a comparative analysis. Washington DC: World Bank, 2019. Available: https://papers. ssrn.com/sol3/papers.cfm?abstract_id=3368579\# [Accessed 5 Apr 2020].

20 Goodchild M, Perucic A-M, Nargis N. Modelling the impact of raising tobacco taxes on public health and finance. Bull World Health Organ 2016;94:250-7.

21 van Walbeek C. A simulation model to predict the fiscal and public health impact of a change in cigarette excise taxes. Tob Control 2010;19:31-6.

22 Levy DT, Tam J, Kuo C, et al. The impact of implementing tobacco control policies: the 2017 tobacco control policy scorecard. J Public Health Manag Pract 2018;24:448-57.

23 Confronting illicit tobacco trade: a global review of country experiences. Washington DC: World Bank Group, 2019. Available: https://documents.worldbank.org/en/ publication/documents- [Accessed 30 May 2020].

24 Ross H. Controlling illicit tobacco trade: international experience. Cape Town: University of Cape Town, 2015. Available: https://untobaccocontrol.org/kh/taxation/ 
directory-e_library/listing/controlling-illicit-tobacco-trade-international-experience/ [Accessed 30 May 2020].

25 van der Zee K, Vellios N, van Walbeek C, et al. The illicit cigarette market in six South African townships. Tob Control 2020. doi:10.1136/tobaccocontrol-2019-055136. [Epub ahead of print: 11 Mar 2020].

26 Wang S, Merriman D, Chaloupka F. Relative tax rates, proximity, and cigarette tax noncompliance: evidence from a national sample of littered cigarette packs. Public Finance Rev 2019;47:276-311.

27 Guindon GE, Burkhalter R, Brown KS. Levels and trends in cigarette contraband in Canada. Tob Control 2017;26:518-25.

28 Liber AC, Ross $\mathrm{H}, \mathrm{Omar} \mathrm{M}$, et al. The impact of the Malaysian minimum cigarette price law: findings from the ITC Malaysia survey. Tob Control 2015;24:iii83-7.

29 Paraje G, Araya D, Drope J. Illicit cigarette trade in Metropolitan Santiago de Chile. Tob Control 2020;29:68-73.

30 Stoklosa M, Ross H. Contrasting academic and tobacco industry estimates of illicit cigarette trade: evidence from Warsaw, Poland. Tob Control 2014;23:e30-4.

31 Depocen. Illicit cigarette trade study in Vietnam. Hanoi: Depocen, 2019. Available: https://tobacconomics.org/wp-content/uploads/2019/08/DEPOCEN-Vietnam-IllicitCigarette-Trade-Report.pdf [Accessed 9 Feb 2020].

32 Kaplan B, Navas-Acien A, Cohen JE. The prevalence of illicit cigarette consumption and related factors in Turkey. Tob Control 2018;27:442-7.

33 Abascal W, Ramos-Carbajales A. Uruguay: tackling illicit trade in tobacco. in: Sheila Dutta. confronting illicit tobacco trade: a global review of country experiences. Washington DC: World Bank Group, 2019. Available: https://documents.worldbank. org/en/publication/documents-reports/documentdetail/677451548260528135/ confronting-illicit-tobacco-trade-a-global-review-of-country-experiences [Accessed 9 Feb 2020].
34 Heydari G. Marlboro is the only smuggled cigarette which was used in Tehran. An experience from third cigarette pack surveys in Tehran, 2018. Tob Induc Dis 2018;16:A86.

35 ITC. Illegal tobacco products research surveys 2017. Irish tax and customs, statistics and economic research branch, 2018. Available: https://revenue.ie/en/corporate/ documents/research/illegal-tobacco-survey-2017.pdf [Accessed 6 Apr 2020].

36 Chisha Z, Janneh ML, Ross H. Consumption of legal and illegal cigarettes in the Gambia. Tob Control:tobaccocontrol-2019-055055.

37 Saenz de Miera Juarez B, Reynales-Shigematsu LM, Stoklosa M, et al. Measuring the illicit cigarette market in Mexico: a cross validation of two methodologies. Tob Control 2020. doi:10.1136/tobaccocontrol-2019-055449. [Epub ahead of print: $05 \mathrm{Mar}$ 2020].

38 Ahsan A, Wiyono NH, Setyonaluri D, et al. Illicit cigarette consumption and government revenue loss in Indonesia. Glob Health 2014;10:75.

39 Maldonado N, Llorente B, Escobar D, et al. Smoke signals: monitoring illicit cigarettes and smoking behaviour in Colombia to support tobacco taxes. Tob Control 2019. doi:10.1136/tobaccocontrol-2018-054820. [Epub ahead of print: 04 May 2019].

40 Ross $\mathrm{H}$, Vellios N, Batmunkh T, et al. Impact of tax increases on illicit cigarette trade in Mongolia. Tob Control:tobaccocontrol-2018-054904.

41 Goodchild M, Valavan T, Sinha P, et al. Measuring illicit cigarette consumption in India: implications for tobacco control. WHO Bulletin. Available: https://www.who.int/ bulletin/online_first/BLT.20.251447.pdf?ua=1 [Accessed 27 Aug 2020].

42 ATO. Illicit tobacco. Australian Tax Office. Available: https://www.ato.gov.au/General/ The-fight-against-tax-crime/Our-focus/llicit-Tobacco/ [Accessed 9 Feb 2020].

43 Ajmal A, Veng lan U. Tobacco tax and the illicit trade in tobacco products in New Zealand. Aust N Z J Public Health 2015;39:116-20.

44 Little M, Ross H, Bakhturidze G, et al. Illicit tobacco trade in Georgia: prevalence and perceptions. Tob Control 2019. doi:10.1136/tobaccocontrol-2018-054839. [Epub ahead of print: 18 Jan 2019]. 